\title{
Letters
}

\section{Queues and Reference Service}

\section{To the Editor:}

Regazzi and Hersberger's study of four models for delivering reference service at peak periods ( $C b R L$, July 1978) is a welcome addition to analyses of public services effectiveness. However, the student/ professional model that received the highest "effectiveness" rating-and, indeed, all models-assumes that the quality of service remains constant regardless of who interviews patrons and delivers the service.

Using students to "screen and refer" can be justified only if students can $(a)$ accurately diagnose when a reference/research question is hidden beneath a directional inquiry (no mean task!) and (b) are willing to admit the limits of their own knowledge and know that others may be able to go farther. Halldorsson and Murfin (CURL, September 1977) studied precisely these questions; their findings should be weighed by any library planning to use nonprofessionals on the "front line" at reference.

If staff costs/idle time and patron waiting time are paramount, the student/professional model surely bears investigation, but the risk of decreased quality of reference service must also be considered. Careful orientation and supervision of students may somewhat alleviate the problem, but they have implications for the total cost of the model-Julie Blume, Coordinator of User Education, Health Sciences Library, University of North Carolina at Chapel Hill.

\section{On-Line Search Services}

\section{To the Editor:}

Charging fees for on-line services is declared to be a necessity by James Cogswell in the July 1978 issue of $C \downarrow R L$. His first attempt to justify charging them is based on a questionnaire that was limited to those who have already used his service, that is, those who have already demonstrated their ability and willingness to pay the fees. Apparently he is not concerned about those who cannot afford to pay.

Then he argues that the only alternatives to charging fees are to cut back existing services or to discontinue on-line services. That is, of course, the dilemma of all library decisions, whether it is to buy a book, a new abstracting service, or an OCLC terminal. The choices, however, are not as limited as the ones he offers. It is possible to recover some of the costs from the time saved by reference librarians because automatic searching is so much faster than manual searching. Some money can be saved by eliminating indexing and abstracting services that are duplicated on-line. And a library can be selective in the use of the on-line terminal to keep the costs within reasonable limits. If the terminal is used as just another reference tool, the reference librarians can determine whether an on-line search would be more cost-effective than a manual search.

Finally, Cogswell chose the worst possible solution to the problem: partial library subsidy. In fairness to the users who cannot afford to pay, the library should recover the total cost of on-line services if it is going to charge fees at all. To the extent that staff time, equipment costs, and general overhead costs are diverted to on-line services, Cogswell's solution penalizes the user who cannot afford to pay. Rather than cut any portion of the existing free services, the library should charge the full cost to the few users who can afford it. But a limited program of on-line service without fees can be made available to as many as possible on the basis of need as determined by the reference librarians. Those users who cannot be served by such a limited program may always turn to commercial information brokers. As I see it, this is the only way to protect the rights of poor students and faculty. - R. Dean Galloway, Library Director, California State College, Stanislaus. 


\section{Response}

To the Editor:

My purpose in discussing the questionnaire concerning on-line search services at Penn was not to "justify" fees for service but rather to demonstrate a perceived change in user attitude toward those fees. Since results of the questionnaire closely paralleled those of a similar MIT survey, I felt the questionnaire significant. The only "justification" I offer for charging fees is the lack of an alternative source for necessary funds.

Mr. Galloway offers no evidence that his cost-saving measures would constitute such a source. His first suggestion is to recover costs through savings in staff time. Such savings could be realized only in libraries where staff members have previously performed personalized, on-demand, manual literature searches. As my article points out, this has simply not been a traditional service in noncommercial libraries. His second alternative is to eliminate subscriptions to hardcopy sources. Apparently my point that this would further increase costs for the online product was lost on Mr. Galloway. Furthermore, the elimination of manual indexes would make impossible Mr. Galloway's third suggestion-using on-line searches "selectively"-because users would then have no option but to request an on-line search. What is more important, I know of no academic library that is not already being "selective" in using the computer as merely one of many potential reference tools.

Even considering such selectivity on the part of libraries, there has been a steady and dramatic increase in the number of users who can demonstrate a legitimate "need" for on-line services. Mr. Galloway proposes to meet this need through existing library funds, but this ensures that progressively more money will be diverted toward on-line searching to serve an evergrowing user population. My proposal provides a means for each library to determine what proportion of the costs it is best able to bear while avoiding the requirement of patron financial statements to determine ability or inability to pay.-James A. Cogswell.

\section{Participative Management}

To the Editor:

Dennis Dickinson's thoughtful article on participative management ( $C \mho R L$, July 1978) does not address a number of significant trends in academic library administration. We are, whether we like it or not, being moved closer and closer to the faculty. Computerization has taken hold in technical services. Bibliographic instruction has come of age, and the debates on faculty status continue. Academic libraries already exist in which a minimal number of professionals (if any) serve in nonpublic service areas.

Mr. Dickinson indicates that the crux of a library operation is the movement of materials "through a coordinated and integrated system from publisher to patron." Academic librarians today are not so much concerned with the movement as with use of the product. More and more time is devoted to teaching, curriculum planning, faculty liaison, course development, and the preparation of bibliographic guides. Collegiality often develops on its own as the most efficient means of meeting these concerns.

Having worked in one of Mr. Dickinson's "pernicious models" as well as several traditional ones, I feel that his criticisms of the committee system and absolute democracy are well taken. His insistence on a strict hierarchical approach, however, could have serious implications for both library instruction and faculty status. I would suggest instead an investigation of the relationship between participatory management, library instruction, and faculty status.-Thomas $H$. Patterson, Head, Reference Department, University of Maine at Orono.

\section{Response}

\section{To the Editor:}

As $\mathrm{Mr}$. Petterson indicates, I do indeed believe that "the crux of a library operation is the movement of materials" from publisher to patron. The crux of our disagreement is not, however, that "academic librarians today are not so much concerned with the movement as with the use of the product"-for I grant that-but rather which of these should be the focus of con- 
cern given the need for strategic allocation of increasingly scarce resources.

As "more and more time is devoted to teaching ...." less and less will be given to the traditional and necessary logistic functions in libraries, given finite and stable resources. Inasmuch as the latter are available in only the most fortunate academic libraries today, the imbalance is further aggravated with the result that libraries will eventually find themselves expending all of their resources trying to sell products and services they then cannot provide-a practice that, in the private sector, is known as false advertising, is illegal, and is usually self-corrective. In public service institutions, on the other hand, such a fraud may, unfortunately, be tolerated for some time.

Mr. Patterson and I also seem to be in essential disagreement with regard to faculty status for librarians. As I indicated in the article, I believe it to be an inappropriate model for a number of reasons, some of which I mentioned, and I consider profaculty-status arguments based on the need for and existence of library instruction programs to be, at best, weak-as are most of the programs and the reasons for their existence.

Thus, if Mr. Patterson's objections rest entirely on the possible "serious implications" that a hierarchical administrative structure may have for library instruction and faculty status, and if the implications are understood as moving in the direction of rethinking and radically redesigning these, then I can only say that such a structure may offer even more benefits for libraries than I thought.-Dennis W. Dickinson.

\section{To the Editor:}

In "Some Reflections on Participative Management in Libraries" ( $C \mho R L$, July 1978, p. 253-62), Dennis W. Dickinson uses badly reasoned, illogically presented arguments to attack what he calls the increasing "hodgepodge of disparate proposals generally glossed under the rubric of 'participative management."

Given the numerous pro-administration and anti-staff arguments he marshals, his conclusion is actually surprisingly moderate. While finally advocating "extensive and intensive consultation between administration and staff, but with the ultimate decisionmaking authority and attendant accountability unequivocally lodged with the library administration," the total burden of his remarks would support a position he claims he is not taking: "for a dictatorial, autocratic, or oligarchic management style in libraries."

Dickinson characterizes library staff members as primarily motivated by a desire to "secure the status quo" and library administrators as "informed," having "the vision, leadership ability, and practical good sense to direct the library properly." Administrators are also said to be the only librarians to whom a "decision-making context" is available. Yet, if staff are so interested in maintaining the status quo, why the clamor for change in library administration to which the article is addressed? In fact, history and experience teach us that it is those with the greatest power who fear change the most.

And if those traditionally in charge (administrators) are doing such a good job, why does Dickinson assert that individuals in libraries are being promoted on "seniority and performance which is not unsatisfactory"; why have libraries (i.e., administrators) been notably "unsuccessful in developing effective programs for recruiting, assessing, and developing a competent staff"; and why are so many librarians being allowed by their administrators to continue to perform "low-level, routine functions"?

There are real problems with the traditional hierarchical model. They include uninformed decision making based on remoteness from the operational level, misguided decision making based on the narrow perspective of a single individual, and autocratic decision making that neglects to consider the concrete effects of implementation on people and the jobs they are trying to do. These problems are minimized in proportion to the amount of sharing allowed in the policy discussion, decision, and implementation processes.

The assumption that only certain elite have the ability to set intelligent policy is not only arrogant, but false. Given access to the necessary information and the opportunity to discuss ideas and proposals with colleagues, intelligent and dedicated librarians are capable of assuming authority and taking 
responsibility for the making and implementation of effective policy. The more intelligent minds are brought to bear on a situation in which the participants are informed and involved, the more intelligent a decision is likely to result.

The fear of diffusion of responsibility in groups, which Dickinson raises, is greatly exaggerated. A group of people directly concerned with and affected by a problem will assume collective responsibility for the results of their actions. They are the ones who must live most intimately with those results.

While library administrators often discuss the extent to which the organization is meeting the needs of those it serves, they rarely consider the extent to which it meets the equally important needs of those who serve. Those to be affected most directly by a proposed decision should be most directly involved in its formulation. This is not only the most humane approach but also the most salutary in terms of effective implementation at the operational level.-Wes Daniels, Senior Acquisitions Librarian, Harvard Law School Library.

\section{Response}

\section{To the Editor:}

Most of Daniels' remarks seem to stem from his failure to read carefully and/or to follow out the logical implications of statements made in the article.

To begin with, the assertation that my remarks may support an argument "for a dictatorial, autocratic, or oligarchic management style . . .," even if true, would say nothing about what $I$, in fact, advocate. That Daniels implies they do clearly, simply, and graphically demonstrates that Dan Gore is correct in his contention that some librarians cannot make the important logical distinction between the necessary and the possible. Moreover, when taken in aggregate, as Daniels claims to be doing, the remarks clearly do not extend such support.

In the same vein, Daniels alleges that I "characterize" library administrators as in- formed, etc. In fact, what I said was that administrators are paid to have certain qualities-quite a different statement. One has only to look around to find numerous intramural examples of persons who are being paid to do things they will not or cannot do-and by no means are they all administrators. But paying anyone to do something and then setting up a structure that ensures they cannot do it is the height of folly. I am thus not arguing that all library administrators are doing "a good job," as Daniels mistakenly believes, but rather that it is, logically, only they who can do the job of running a library well for structural, not personal, reasons.

As to why so many librarians are allowed to continue performing low-level, routine functions, the answer is, as the article points out, that that is simply the nature of much of library work.

I addressed specifically the problems with hierarchical models that concern Danielsalthough perhaps in parts of the article he skipped in his haste to erect men of straw to pummel. I will not, therefore, bore your more attentive readers with a rehash.

I could not agree more with Daniel's opinion that "given access to the necessary information ... , etc." The point, which I thought I had stated clearly in the article, is just exactly that granting such access to large numbers of people is not practicable-if, indeed, it is possible at all.

Daniels' "more is better" philosophy of problem solving, while it has a kind of superficial, populist plausibility, is simply not borne out by any research in group dynamics of which I am aware. A careful reading of my article will, however, disclose that I have no argument with his ideas on staff involvement in deliberations preceding policy decisions-nor he with mine. Such notions fit quite comfortably into the consultative management style I espouse.

In short, Daniels' objections seem to be principally the result of a highly imaginative interpretation of the article, which is based on a less-than-thorough reading.-Dennis W. Dickinson. 

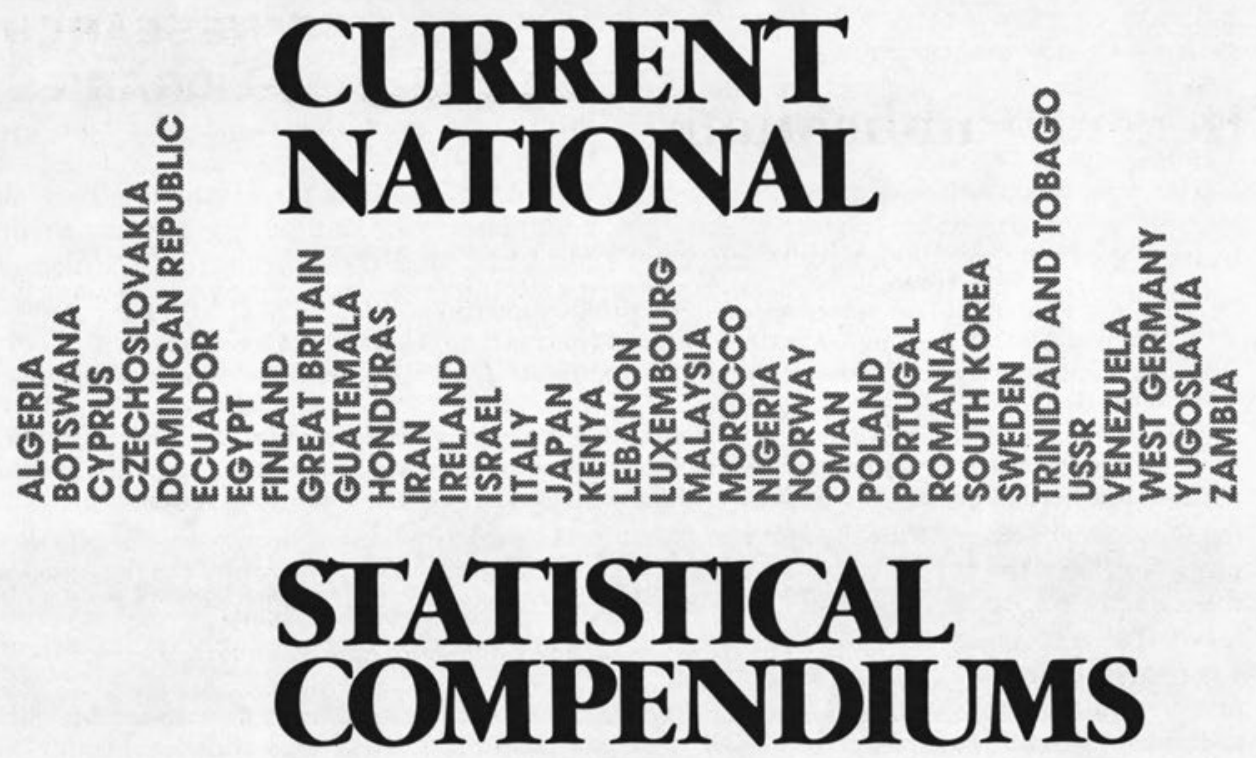

\section{Latest editions now available on microfiche}

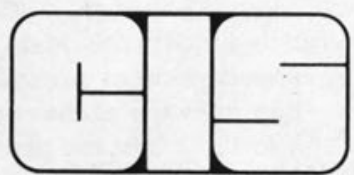

Congressional Information Service, Inc. 7101 Wisconsin Avenue, Suite 900 Washington, D.C. 20014 Telephone (301) 654-1550
A nation's statistical compendium or yearbook is an excellent source of information on its economic, political, social, and cultural conditions. Prepared by national experts and agencies, and generally published in English or another Western European language, these detailed compilations and analyses are indispensable reference and research sources. They are available in a micropublishing program that is updated annually, and at present offers more than 400 editions from over 100 nations principally from 1970 through 1977.

Microfiche copies may be purchased in a complete collection, or selectively, by continental groups of countries, by individual countries, or by individual titles. Costs are relatively modest, and progressive discounts apply to larger acquisitions and standing orders. A comprehensive bibliography is supplied free of charge with most purchases.

At last, national statistical compendiums are easy to acquire and use. For details and prices, please contact us. 